\title{
Qualidade interna de ovos submetidos a diferentes tipos de revestimento e armazenados por 35 dias a $25^{\circ} \mathrm{C}$
}

\section{Internal quality of eggs subjected to different types of coating and stored for 35 days at $25^{\circ} \mathrm{C}$}

\author{
Aniele Pissinati ${ }^{1}$; Alexandre Oba ${ }^{2 *}$; Fábio Yamashita ${ }^{3}$; Caio Abercio da Silva ${ }^{4}$; \\ João Waine Pinheiro'²; Juliana Maria Martinez Roman ${ }^{5}$
}

\begin{abstract}
Resumo
Este trabalho teve por objetivo avaliar a qualidade interna de ovos submetidos a dois tipos de revestimento: gelatina a 3\%, óleo mineral comercial e sem revestimento (controle). Foram utilizados 180 ovos brancos, com peso médio de $62 \mathrm{~g}$, provenientes de galinhas poedeiras da linhagem Shaver White. Estes ovos foram armazenados a uma temperatura de $25^{\circ} \mathrm{C}$ em uma BOD, durante 35 dias e foram analisados a cada sete dias. Foram avaliados a porcentagem de gema, porcentagem de albúmen, porcentagem de casca, porcentagem de perda de peso, unidade Haugh (UH), gravidade específica, índice gema, $\mathrm{pH}$ do albúmen, $\mathrm{pH}$ da gema e coloração da casca. Os resultados mostraram que o tempo de armazenamento prejudica a qualidade dos ovos e que o tratamento com revestimento com óleo mineral foi o que proporcionou melhor qualidade interna destes, enquanto que o revestimento com gelatina a $3 \%$ apresentou qualidade intermediária e o tratamento sem revestimento, a pior qualidade interna dos ovos, mostrando assim, a necessidade da utilização de algum tipo de revestimento para aumentar a vida de prateleira dos mesmos.
\end{abstract}

Palavras-chave: Biofilme de gelatina, óleo mineral, qualidade do ovo, tempo de armazenamento

\begin{abstract}
This study aimed to evaluate the internal quality of eggs subjected to three different types of coatings: no coating (control); 3\% gelatin and mineral oil. We used 180 white eggs, with an average weight of $62 \mathrm{~g}$, from laying hens strain Shaver White. Those eggs were stored at a temperature of $25^{\circ} \mathrm{C}$ in a BOD during 35 days and were analyzed every seven days. We evaluated yolk, albumen, shell and weight loss percentage, Haugh units, specific gravity, yolk index, albumen and yolk pH and egg shell color. The results showed that storage time affects the quality of the eggs and the treatment coating the egg with mineral oil were provided the better internal quality of eggs, while the gelatin coating showed intermediate quality and without coating treatment, a poorer quality internal eggs, thus showing necessary to use some kind of coating to increase the shelf life of eggs.
\end{abstract}

Key words: Gelation of biofilm, mineral oil, egg quality, storage time

\footnotetext{
${ }^{1}$ Zootecnista, Discente de Mestrado da Universidade Estadual de Londrina, UEL, Londrina, PR. E-mail: aniele_pissinati@hotmail. com

${ }^{2}$ Zootecnistas, Profs. Drs. da UEL, Londrina, PR. E-mail: oba@uel.br; jwaine@uel.br

${ }^{3}$ Eng $^{\circ}$ de Alimentos, Prof. Dr. da UEL, Londrina. E-mail: fabioy@uel.br

${ }^{4}$ Médico Veterinário, Prof. Dr. da UEL, Londrina, PR. E-mail: casilva@uel.br

${ }^{5}$ Zootecnista, UEL, Londrina, PR. E-mail: juliroman05@hotmail.com

* Autor para correspondência
} 


\section{Introdução}

O ovo é considerado um alimento dos mais completos, por fornecer elementos essenciais à saúde, tais como proteína, vitaminas e minerais (MURAKAMI et al., 1994). Segundo Lana (2000), o albúmen e a gema apresentam em sua composição química cerca de $28 \%$ de proteína, $0,7 \%$ de carboidratos, $33 \%$ de gorduras e $0,8 \%$ de minerais. Considerando este alto valor nutritivo, o ovo é recomendado como alimento para uma dieta variada e equilibrada. Devido às suas características funcionais tecnológicas, é amplamente utilizado pelas indústrias nos mais diversos produtos e preparações. Além disso, faz parte do hábito alimentar da população brasileira, principalmente por apresentar preços acessíveis (PLETI; LIMA; CANDIDO, 2009).

O ovo é um alimento perecível, e começa a perder sua qualidade interna imediatamente após a postura (SOUZA; SOUZA; LIMA, 1993). A redução da qualidade interna dos ovos está associada principalmente à perda de água e de dióxido de carbono, durante o período de armazenamento, e é proporcional à elevação da temperatura do ambiente (CRUZ; MOTA, 1996).

Com o intuito de aumentar a vida de prateleira dos ovos, podem-se criar barreiras para evitar perdas e as trocas entre o meio interno e externo, visto que durante o armazenamento há perda de umidade e dióxido de carbono via poros da casca, o que causa mudanças na qualidade do albúmen e gema, bem como a perda de peso dos ovos (STADELMAN, 1995). Dentre as possíveis barreiras, o óleo mineral tem se mostrado eficiente na conservação dos ovos. Outro possível revestimento que vem sendo utilizado em frutas, e que tem demonstrado efeitos benéficos sobre a conservação de frutas, aumentado à vida de prateleira é o biofilme a base de gelatina (FAKHOURI et al., 2007).

Dessa forma, este trabalho teve por objetivo avaliar a qualidade de ovos submetidos a diferentes formas de revestimento (gelatina a 3\% e óleo mineral) e sem revestimento, armazenados por um período de até 35 dias a uma temperatura de $25^{\circ} \mathrm{C}$.

\section{Material e Métodos}

O experimento foi realizado no Laboratório de Análise de Alimentos e Nutrição Animal da Universidade Estadual de Londrina. Para a realização das análises foram utilizados 180 ovos brancos, com peso médio de $62 \mathrm{~g}$, provenientes de galinhas poedeiras da linhagem Shaver White, os quais foram submetidos a diferentes tipos de tratamento (sem revestimento - controle, revestido com gelatina a $3 \%$ e óleo mineral) e armazenados por até 35 dias a uma temperatura de $25^{\circ} \mathrm{C}$.

$\mathrm{O}$ revestimento com gelatina consistiu em submeter os ovos em imersão na solução com inclusão de $3 \%$ de gelatina e em seguida colocados em suporte de tela para a secagem em temperatura ambiente por duas horas. Para o óleo mineral utilizou-se uma marca comercial, onde os mesmos foram submetidos por processos semelhantes ao da gelatina. Após secagem, os ovos foram mantidos em caixas de poupa de celulose, as quais foram armazenadas em uma BOD a uma temperatura de $25{ }^{\circ} \mathrm{C}$.

Para avaliação da qualidade dos ovos, foram analisadas semanalmente características de porcentagem de perda de peso; relação entre a casca, gema e o albúmen; unidade Haugh (UH); gravidade específica; índice gema e $\mathrm{pH}$ da gema e albúmen, conforme Souza et al. (1994). Além destas, foram avaliadas também a coloração da casca do ovo.

A determinação da porcentagem de perda de peso consistiu em pesar os ovos no dia zero e após cada tempo de armazenagem. Pela diferença entre o peso no início e no final do tempo de armazenagem foi obtida a perda de peso em gramas. Este valor foi dividido pelo peso do ovo no início do armazenamento, e multiplicado por 100, gerando os dados de perda de peso em porcentagem. 
A relação entre casca, gema e o albúmen foi determinado através da pesagem do ovo e posterior quebra e pesagem da gema. Em seguida a casca foi lavada para retirar o albúmen e secas a temperatura ambiente por um período de 24 horas. Através da pesagem da casca, o albúmen foi determinado pela diferença do peso do ovo em relação ao peso da gema e da casca.

Para determinar a unidade Haugh, os ovos foram quebrados sobre uma superfície plana para medir a altura do albúmen com o uso de um micrômetro. A medida foi realizada no ponto médio entre a extremidade da gema e a extremidade externa do albúmen mais espessa. Os valores de unidade Haugh levam em consideração a relação logarítmica entre a altura do albúmen denso e o peso do ovo. Para o cálculo, aplicou-se a seguinte equação: $\mathrm{HU}=100$ $\log \left(\mathrm{H}+7,57-1,7 \mathrm{~W}^{0,37}\right)$, onde $\mathrm{H}$ é a altura do albúmen em milímetros e o $\mathrm{W}$ é o peso do ovo em gramas (SOUZA et al., 1994).

O Índice Gema (IG) foi obtido através da formula: IG = altura da gema/largura da gema, sendo que para determinar a altura da gema foi utilizado um micrometro e para a largura desta um paquímetro (SOUZA et al., 1994).

Para determinar o valor do $\mathrm{pH}$ da gema e do albúmen, utilizou-se um pHmetro digital da marca Testo, modelo 205 (SOUZA et al., 1994).

Foram avaliadas as características físicas da casca do ovo através das analises de gravidade específica e coloração. A gravidade específica (GE) do ovo foi calculada pela seguinte equação: $\mathrm{GE}=$ peso do ovo/ (peso do ovo na água x correção da temperatura). O fator de correção utilizado foi obtido através da equação de Kell (1975), na qual a densidade da água em função da temperatura pode ser calculada como: $\mathrm{D}=\left(0,9998676+17,801161 * 10^{-3} \mathrm{t}-\right.$ $7,942501 * 10^{-6} \mathrm{t}^{2}-52,56328 * 10^{-9} \mathrm{t}^{3}+137,6891 * 10^{-}$ $\left.{ }^{12} t^{4}-364,4647 * 10^{-15} t^{5}\right) /\left(1+17,735441 * 10^{-3} t\right)$ onde $t$ é a temperatura em graus Celsius.
Para as análises de coloração da casca foi utilizado o colorímetro Minolta, modelo CR 10, onde foi determinada a luminosidade e a intensidade de amarelo.

Foi adotado um delineamento inteiramente ao acaso, em esquema fatorial $3 \times 5$ (tratamentos e período de armazenamento), com seis repetições, sendo que cada unidade experimental era composta por dois ovos. As análises estatísticas foram realizadas por meio de análise de variância utilizando-se o programa Sistemas de Análises Estatísticas e Genéticas-SAEG, desenvolvido pela Universidade Federal de Viçosa (2007). As médias foram submetidas ao teste de Tukey a 5\% de significância.

\section{Resultados e Discussão}

Pelos resultados apresentados, pode-se observar que houve diferença $(\mathrm{P}<0,01)$ para perda de peso, onde os ovos revestidos com óleo mineral apresentaram a menor perda e os ovos sem revestimento foram os que apresentaram a maior perda de peso (Tabela 1). Segundo Cherian et al. (1990), quando os ovos são armazenados por longos períodos, pode ocorrer redução do peso do ovo devido à perda de água. Esta perda de peso ocorre também em função das reações de transformação que ocorre nos ovos, visto que segundo Seibel et al. (2005) durante o período de armazenamento a ovoalbumina se transforma em S-ovoalbumina e ocorre a dissociação do complexo ovomucinalisozima com a destruição do gel de ovomucina. Estas reações são importantes no plano tecnológico, pois provocam a perda ou redução das propriedades gelificantes e espumantes da viscosidade do albúmen, tornando-os liquefeitos e também facilita a evaporação da água através dos poros da casca. 
Tabela 1. Resultados de porcentagem de gema, albúmen, casca, e perda de peso de ovos submetidos a diferentes tipos de tratamentos e armazenados a $25^{\circ} \mathrm{C}$, durante 35 dias.

\begin{tabular}{lllll}
\hline \multicolumn{1}{c}{ Tratamento } & \% gema & \% albúmen & \% casca & \% perda de peso \\
\hline Tipos de revestimento (R) & & & & \\
Controle & $31,68 \mathrm{a}^{1}$ & $58,20 \mathrm{~b}$ & 10,12 & $5,38 \mathrm{a}$ \\
Óleo Mineral & $29,58 \mathrm{~b}$ & $60,53 \mathrm{a}$ & 9,89 & $1,64 \mathrm{c}$ \\
Gelatina a 3\% & $30,81 \mathrm{ab}$ & $59,11 \mathrm{~b}$ & 10,07 & $4,86 \mathrm{~b}$ \\
\hline Teste F & $8,08^{* *}$ & $9,79^{* *}$ & $3,09^{\mathrm{NS}}$ & $751,33^{* *}$ \\
DMS & 1,26 & 1,27 & 0,23 & 0,25 \\
\hline Períodos Armazenamento (A) & & & & \\
7 dias & $28,96 \mathrm{~b}$ & $61,30 \mathrm{a}$ & $9,74 \mathrm{c}$ & $1,36 \mathrm{e}$ \\
14 dias & $29,23 \mathrm{~b}$ & $60,87 \mathrm{a}$ & $9,90 \mathrm{bc}$ & $2,89 \mathrm{~d}$ \\
21 dias & $30,61 \mathrm{ab}$ & $59,40 \mathrm{ab}$ & $9,99 \mathrm{bc}$ & $3,95 \mathrm{c}$ \\
28 dias & $32,18 \mathrm{a}$ & $57,71 \mathrm{bc}$ & $10,11 \mathrm{ab}$ & $5,10 \mathrm{~b}$ \\
35 dias & $32,48 \mathrm{a}$ & $57,12 \mathrm{c}$ & $10,40 \mathrm{a}$ & $6,49 \mathrm{a}$ \\
\hline Teste F & $11,52^{* *}$ & $14,75^{* *}$ & $7,96^{* *}$ & $430,75^{* *}$ \\
DMS & 1,89 & 1,91 & 0,35 & 0,38 \\
\hline F de interação R X A & $1,79^{\mathrm{NS}}$ & $2,08^{*}$ & $2,03^{\mathrm{NS}}$ & $60,24^{* *}$ \\
\hline CV $(\%)$ & 6,62 & 3,45 & 3,69 & 10,22 \\
\hline
\end{tabular}

Na mesma coluna, médias seguidas de letras diferentes, indicam diferenças estatísticas pelo teste de Tukey $\left(\mathrm{P}<0,01=* *\right.$ e $\left.\mathrm{P}<0,05^{*}\right)$; $\mathrm{NS}=$ Não significativo.

Fonte: Elaboração dos autores.

Devido à barreira física proporcionado pelos revestimentos, ocorre menor liquefação do albúmen, e consequentemente proporciona uma menor perda deste (Tabela 1), onde o revestimento com óleo mineral proporcionou a maior porcentagem de albúmen e o controle a pior porcentagem. As reações que ocorrem no albúmen estão diretamente relacionadas com a porcentagem de gema, visto que com a liquefação do albúmen ocorre maior produção de água. Segundo Narushin (1997) a água da albumina atravessa a membrana vitelínica por osmose e é retida na gema. $\mathrm{O}$ excesso de água na gema determina o aumento do seu volume, levando ao enfraquecimento da membrana vitelínica. Isto faz com que a gema pareça maior e achatada quando o ovo é observado em uma superfície plana após a sua quebra. Isto pode ser observado para a porcentagem de gema, onde o tratamento controle foi o que apresentou a menor $(\mathrm{P}<0,01)$ porcentagem de albúmen e a maior $(\mathrm{P}<0,01)$ porcentagem de gema, enquanto o revestimento com óleo mineral apresentou a maior $(\mathrm{P}<0,01)$ porcentagem de albúmen e a menor $(\mathrm{P}<0,01)$ porcentagem de gema. Já a porcentagem de casca não foi alterada em função aos diferentes tratamentos e períodos de armazenamento.

Como foi observado, as porcentagens das partes dos ovos e perdas de peso são influenciadas principalmente por alterações que ocorrem no albúmen. Pode-se observar na Tabela 2, através do desdobramento entre o tipo de revestimento e os períodos de armazenamento, que diferenças na porcentagem de albúmen ocorreram a partir de $28^{\circ}$ dia de armazenamento, sendo que o tratamento com revestimento com óleo mineral proporcionou a maior $(\mathrm{P}<0,01)$ porcentagem de albúmen e o tratamento sem revestimento, a menor $(\mathrm{P}<0,01)$, enquanto que o tratamento com revestimento com gelatina a 3\% não diferiu em relação a ambos os tipos de revestimentos. Isto mostra que o revestimento com óleo mineral mostrou-se mais eficiente, enquanto que o revestimento com gelatina a $3 \%$ proporcionou pouca melhora em relação ao controle. Resultados semelhantes foram obtidos por Waimaleongora-Ek 
et al. (2009) e Mendonça et al. (2013) ao revestir ovos de galinha e codorna, respectivamente, com óleo mineral observaram menores perdas de peso e qualidade interna dos ovos. Avaliando a utilização de óleos de origem vegetal como revestimento de ovos, Nongtaodum et al. (2013) observaram menor perda de peso dos ovos revestidos em relação aos revestidos com glicerol ou sem revestimento.

Tabela 2. Desdobramento da interação entre as diferenças de tipos de revestimento e períodos de armazenamento para porcentagem de albúmen de ovos armazenados a $25^{\circ} \mathrm{C}$.

\begin{tabular}{lcccc}
\hline \multirow{2}{*}{ Períodos de Armazenamento } & \multicolumn{3}{c}{ Porcentagem de albúmen } & \multirow{2}{*}{ Teste F } \\
\cline { 2 - 4 } & Controle & Óleo Mineral & Gelatina a 3\% & \\
\hline 7 dias & $60,57 \mathrm{aA}^{1}$ & $61,56 \mathrm{aA}$ & $61,78 \mathrm{aA}$ & $0,59^{\mathrm{NS}}$ \\
14 dias & $60,58 \mathrm{aA}$ & $61,53 \mathrm{aA}$ & $60,50 \mathrm{abA}$ & $0,47^{\mathrm{NS}}$ \\
2 dias & $59,74 \mathrm{aA}$ & $60,00 \mathrm{aA}$ & $58,54 \mathrm{abcA}$ & $0,79^{\mathrm{NS}}$ \\
28 dias & $55,27 \mathrm{bB}$ & $59,90 \mathrm{aA}$ & $57,87 \mathrm{bcAB}$ & $8,04^{* *}$ \\
35 dias & $54,87 \mathrm{bB}$ & $59,63 \mathrm{aA}$ & $56,87 \mathrm{cAB}$ & $8,20^{* *}$ \\
\hline Teste $\mathrm{F}$ & $11,93^{* *}$ & $1,24^{\mathrm{NS}}$ & $5,71^{* *}$ & \\
\hline
\end{tabular}

${ }^{1} \mathrm{Na}$ mesma linha, médias seguidas de letras maiúsculas diferentes, e na mesma coluna, médias seguidas por letras minúsculas diferentes indicam diferença estatística pelo teste de Tukey $(\mathrm{P}<0,05=*$ e $\mathrm{P}<0,01=* *)$; ${ }^{\mathrm{N}}=$ Não significativo.

Fonte: Elaboração dos autores.

Ao se avaliar o desdobramento da interação entre os diferentes tratamentos para a porcentagem de perda de peso dos ovos em diferentes períodos de armazenamento, pode-se observar na Tabela 3 que aos sete dias de armazenamento a porcentagem de perda de peso dos ovos foi menor $(\mathrm{P}<0,01)$ nos tratamentos que receberam algum tipo de revestimento. Nas análises realizadas com 14, 21 e 28 dias de armazenamento, os ovos revestidos com óleo mineral apresentaram uma menor perda de peso $(\mathrm{P}<0,01)$ em relação ao tratamento controle e aos revestidos com gelatina a 3\%. Já nas análises realizadas aos 35 dias de armazenamento os diferentes tipos de revestimento apresentaram resultados distintos, onde o óleo mineral proporcionou menor $(\mathrm{P}<0,01)$ porcentagem de perda de peso e o controle a maior $(\mathrm{P}<0,01)$ porcentagem de perda de peso, enquanto que o revestimento com gelatina a $3 \%$, ocasionou perdas intermediárias. Ao se avaliar a porcentagem de perda de peso dentro do tratamento controle e revestido com gelatina a 3\%, pode-se notar que estes apresentaram características semelhantes. Enquanto que o tratamento com revestimento com óleo mineral proporcionou uma dinâmica de perda de peso pouco alterada durante o armazenamento, mostrando-se eficiente no controle da perda de peso. Isto ocorre porque durante o armazenamento há perdas de umidade e dióxido de carbono pelos poros da casca e o revestimento com óleo mineral reduz os poros e conseqüentemente menor é a perda, proporcionando uma melhor qualidade dos ovos e menor perda de peso.

Quanto ao comportamento dos ovos diante do período de armazenamento, observa-se maior porcentagem de perda durante os períodos iniciais, isto é, até o $14^{\circ}$ dia e depois do $28^{\circ}$ dia. Enquanto que para a porcentagem dos componentes dos ovos, maiores transformações foram observadas no $28^{\circ}$ dia. Isto provavelmente ocorre, pois no período inicial ocorrem grandes trocas entre o meio interno e externo, promovendo alterações nos constituintes dos ovos e depois de 28 dias de armazenamento, pois a qualidade interna dos ovos não é satisfatória, visto que o albúmen está bem liquefeito, facilitando assim a perda de água. Resultados semelhantes foram observados por Bacurau et al. (1994) que ao estudarem a preservação de ovos de galinha por revestimento observaram que tanto para os 
ovos revestidos com óleo mineral, bem como sem revestimento, as perdas de peso foram maiores nos períodos iniciais e depois de 21 dias de armazenamento a temperatura ambiente.

Observa-se na Tabela 4, que os ovos revestidos com óleo mineral apresentaram melhor $(\mathrm{P}<0,01)$ unidade Haugh e os ovos sem revestimento a pior $(\mathrm{P}<0,01)$, ficando o tratamento com revestimento com gelatina a 3\%, um valor intermediário. Segundo Berardinelli et al. (2003) um valor alto para unidade Haugh está associado a ovos de boa qualidade e como podemos observar neste trabalho, os processos de revestimento apesar de apresentarem resultados distintos, mostraram-se eficientes na manutenção da qualidade interna dos ovos, enquanto que o tratamento sem revestimento, mostrou-se inadequado.

Tabela 3. Desdobramento da interação entre as diferenças de tipos de revestimento e períodos de armazenamento para porcentagem de perda de peso de ovos armazenados a $25^{\circ} \mathrm{C}$.

\begin{tabular}{lrrrr}
\hline \multirow{2}{*}{ Períodos de Armazenamento } & \multicolumn{3}{c}{ Porcentagem de Perda de Peso } & \multirow{2}{*}{ Teste F } \\
\cline { 2 - 4 } & Controle & Óleo Mineral & Gelatina a 3\% & \\
\hline 7 dias & $2,07 \mathrm{eA}^{1}$ & $0,87 \mathrm{cB}$ & $1,14 \mathrm{eB}$ & $14,43^{* *}$ \\
14 dias & $3,83 \mathrm{dA}$ & $1,49 \mathrm{bcB}$ & $3,34 \mathrm{dA}$ & $56,12^{* *}$ \\
21 dias & $5,29 \mathrm{cA}$ & $1,75 \mathrm{abB}$ & $4,82 \mathrm{cA}$ & $135,78^{* *}$ \\
28 dias & $6,78 \mathrm{bA}$ & $1,77 \mathrm{abB}$ & $6,76 \mathrm{bA}$ & $305,70^{* *}$ \\
35 dias & $8,92 \mathrm{aA}$ & $2,34 \mathrm{aC}$ & $8,22 \mathrm{aB}$ & $480,26^{* *}$ \\
\hline Teste $\mathrm{F}$ & $256,35^{* *}$ & $10,40^{* *}$ & $284,48^{* *}$ & \\
\hline
\end{tabular}

${ }^{1} \mathrm{Na}$ mesma linha, médias seguidas de letras maiúsculas diferentes, e na mesma coluna, médias seguidas por letras minúsculas diferentes, indicam diferença estatísticas pelo teste de Tukey $(\mathrm{P}<0,05=*$ e $\mathrm{P}<0,01=* *)$.

Fonte: Elaboração dos autores.

Tabela 4. Resultados da Unidade Haugh (UH), gravidade específica, índice gema e pH do albúmen e da gema submetidos a diferentes tipos de tratamento e armazenados a $25^{\circ} \mathrm{C}$, durante 35 dias.

\begin{tabular}{lccccc}
\hline \multicolumn{1}{c}{ Tratamento (R) } & $\mathrm{UH}$ & $\begin{array}{c}\text { Gravidade } \\
\text { Específica }\left(\mathrm{g} / \mathrm{cm}^{3}\right)\end{array}$ & Índice Gema & $\mathrm{pH}$ Albúmen & $\mathrm{pH}$ Gema \\
\hline Controle & $27,35 \mathrm{c}^{1}$ & $1,045 \mathrm{c}$ & $0,23 \mathrm{c}$ & $9,46 \mathrm{a}$ & $6,26 \mathrm{a}$ \\
Óleo Mineral & $73,47 \mathrm{a}$ & $1,088 \mathrm{a}$ & $0,38 \mathrm{a}$ & $8,34 \mathrm{c}$ & $6,35 \mathrm{a}$ \\
Gelatina a 3\% & $60,01 \mathrm{~b}$ & $1,051 \mathrm{~b}$ & $0,34 \mathrm{~b}$ & $8,78 \mathrm{~b}$ & $6,28 \mathrm{a}$ \\
\hline Teste F & $289,00^{* *}$ & $499,46^{* *}$ & $238,91^{* *}$ & $284,69^{* *}$ & $0,67^{\mathrm{NS}}$ \\
DMS & 4,72 & 0,003 & 0,02 & 0,11 & 0,19 \\
\hline Per. de Armazenamento (A) & & & & \\
7 dias & $66,15 \mathrm{a}$ & $1,082 \mathrm{a}$ & $0,37 \mathrm{a}$ & $8,75 \mathrm{~b}$ & $6,13 \mathrm{~b}$ \\
14 dias & $57,57 \mathrm{~b}$ & $1,076 \mathrm{~b}$ & $0,35 \mathrm{a}$ & $8,85 \mathrm{ab}$ & $6,27 \mathrm{ab}$ \\
21 dias & $51,16 \mathrm{bc}$ & $1,068 \mathrm{c}$ & $0,32 \mathrm{~b}$ & $8,85 \mathrm{ab}$ & $6,31 \mathrm{ab}$ \\
28 dias & $49,28 \mathrm{~cd}$ & $1,048 \mathrm{~d}$ & $0,29 \mathrm{~b}$ & $8,84 \mathrm{~b}$ & $6,51 \mathrm{a}$ \\
35 dias & $43,90 \mathrm{~d}$ & $1,035 \mathrm{e}$ & $0,25 \mathrm{c}$ & $9,01 \mathrm{a}$ & $6,27 \mathrm{ab}$ \\
\hline Teste F & $22,49^{* *}$ & $205,17^{* *}$ & $49,40^{* *}$ & $4,97^{* *}$ & $3,58^{*}$ \\
DMS & 7,13 & 0,005 & 0,03 & 0,17 & 0,28 \\
\hline F interação R X A & $1,84^{\mathrm{NS}}$ & $30,51^{* *}$ & $1,52^{\mathrm{NS}}$ & $1,49^{\mathrm{NS}}$ & $3,22^{* *}$ \\
\hline CV $(\%)$ & 14,26 & 0,55 & 8,92 & 2,06 & 4,78 \\
\hline
\end{tabular}

${ }^{1} \mathrm{Na}$ mesma coluna, médias seguidas de letras diferentes, indicam diferenças estatísticas pelo teste de Tukey $\left(\mathrm{P}<0,01={ }^{* *}\right.$ e $\mathrm{P}<0,05$ $\left.={ }^{*}\right) ;{ }^{\text {NS }}=$ Não significativo.

Fonte: Elaboração dos autores. 
Os valores de gravidade específica e índice gema dos ovos também mostraram resultados semelhantes, onde os melhores $(\mathrm{P}<0,01)$ resultados foram obtidos com óleo mineral e os piores $(\mathrm{P}<0,01)$ sem revestimento, enquanto que o revestimento com gelatina foi intermediário. Ao desdobrar a interação entre os diferentes tipos de revestimento e os períodos de armazenamento para os valores de gravidade específica (Tabela 5) observam-se que aos sete, 28 e 35 dias de armazenamento o tratamento controle e o revestido com gelatina a 3\% não apresentaram diferença significativa, sendo que estes apresentaram uma menor gravidade específica, quando comparado ao tratamento com revestimento com óleo mineral. Já nas analises realizadas aos 14 e 21 dias de armazenamento, as diferentes formas de revestimentos foram distintas $(\mathrm{P}<0,01)$, sendo que o revestimento com óleo mineral foi o melhor $(\mathrm{P}<0,01)$ e o controle o pior $(\mathrm{P}<0,01)$ resultado para gravidade específica, enquanto que o revestimento dos ovos com gelatina proporcionou resultados intermediários. Ao se avaliar dentro de cada tipo de revestimento dos ovos, pode-se observar que o tratamento controle e o revestido com gelatina a 3\% apresentaram resultados semelhantes, com redução constante na gravidade específica, enquanto que o tratamento com revestimento com óleo mineral apresentou poucas alterações ao longo do armazenamento. Resultados semelhantes foram obtidos por Mendonça et al. (2013) ao avaliar a gravidade específica de ovos de codorna revestidos com óleo mineral.

Tabela 5. Desdobramento da interação entre as diferenças de tipos de revestimento e os períodos de armazenamento para gravidade específica de ovos armazenados a $25^{\circ} \mathrm{C}$.

\begin{tabular}{lcccc}
\hline \multirow{2}{*}{ Períodos de Armazenamento } & \multicolumn{3}{c}{ Gravidade Específica $\left(\mathrm{g} / \mathrm{cm}^{3}\right)$} & \multirow{2}{*}{ Teste $\mathrm{F}$} \\
\cline { 2 - 4 } & Controle & Óleo Mineral & Gelatina a 3\% & $9,75^{* *}$ \\
\hline 7 dias & $1,08 \mathrm{aB}{ }^{1}$ & $1,09 \mathrm{abA}$ & $1,08 \mathrm{aB}$ & $42,64^{* *}$ \\
14 dias & $1,06 \mathrm{bC}$ & $1,09 \mathrm{aA}$ & $1,07 \mathrm{aB}$ & $109,12^{* *}$ \\
21 dias & $1,05 \mathrm{cC}$ & $1,10 \mathrm{aA}$ & $1,06 \mathrm{bB}$ & $165,55^{* *}$ \\
28 dias & $1,03 \mathrm{~dB}$ & $1,08 \mathrm{bA}$ & $1,03 \mathrm{cB}$ & $294,44^{* *}$ \\
\hline 5 dias & $1,01 \mathrm{eB}$ & $1,08 \mathrm{bA}$ & $1,01 \mathrm{~dB}$ & \\
\hline Teste $\mathrm{F}$ & $129,18^{* *}$ & $6,24^{* *}$ & $130,78^{* *}$ & \\
\hline
\end{tabular}

${ }^{1} \mathrm{Na}$ mesma linha, médias seguidas de letras maiúsculas diferentes, e na mesma coluna, médias seguidas por letras minúsculas diferentes, indicam diferenças estatísticas pelo teste de Tukey $(\mathrm{P}<0,05=*$ e $\mathrm{P}<0,01=* *)$; ${ }^{\mathrm{NS}}=$ Não significativo.

Fonte: Elaboração dos autores.

Para o pH do albúmen foi observado diferença significativa entre os três tratamentos, sendo que o tratamento sem revestimento proporcionou $\mathrm{o}$ maior $(\mathrm{P}<0,01) \mathrm{pH}$ do albúmen, enquanto que os ovos revestidos com óleo mineral o menor $\mathrm{pH}$ $(\mathrm{P}<0,01)$, e os ovos revestidos com gelatina um $\mathrm{pH}$ intermediário.

Nas análises de $\mathrm{pH}$ da gema, pode-se observar através do desdobramento da interação (Tabela
6) que houve apenas diferença $(\mathrm{P}<0,05)$ entre os diferentes tipos de revestimento nas análises realizadas aos 21 e 28 dias de armazenamento, onde aos 21 dias, o tratamento revestido com óleo mineral proporcionou o maior $\mathrm{pH}$ de gema e o tratamento sem revestimento, o $\mathrm{pH}$ mais baixo. Já aos 28 dias de armazenamento, o tratamento sem revestimento proporcionou o maior $\mathrm{pH}$ da gema e o com revestimento com gelatina o menor $\mathrm{pH}$. 
Tabela 6. Desdobramento da interação entre as diferenças de tipo de revestimento e o período de armazenamento para $\mathrm{pH}$ da gema de ovos armazenados a $25^{\circ} \mathrm{C}$.

\begin{tabular}{lcccc}
\hline \multirow{2}{*}{ Período de Armazenamento } & \multicolumn{3}{c}{$\mathrm{pH}$ da Gema de Ovos } \\
\cline { 2 - 5 } & Controle & Óleo Mineral & Gelatina a 3\% & Teste F \\
\hline 7 dias & $6,03 \mathrm{bA} A^{1}$ & $6,17 \mathrm{aA}$ & $6,19 \mathrm{aA}$ & $0,53^{\mathrm{NS}}$ \\
14 dias & $6,17 \mathrm{bA}$ & $6,21 \mathrm{aA}$ & $6,42 \mathrm{aA}$ & $1,20^{\mathrm{NS}}$ \\
2 dias & $6,05 \mathrm{bB}$ & $6,65 \mathrm{aA}$ & $6,24 \mathrm{aAB}$ & $6,23^{*}$ \\
28 dias & $6,80 \mathrm{aA}$ & $6,48 \mathrm{aAB}$ & $6,23 \mathrm{aB}$ & $5,38^{\mathrm{NS}}$ \\
35 dias & $6,26 \mathrm{bA}$ & $6,23 \mathrm{aA}$ & $6,33 \mathrm{aA}$ & $0,17^{\mathrm{NS}}$ \\
\hline Teste $\mathrm{F}$ & $6,58^{* *}$ & $0,57^{\mathrm{NS}}$ & $2,86^{\mathrm{NS}}$ & \\
\hline
\end{tabular}

${ }^{1} \mathrm{Na}$ mesma linha, médias seguidas de letras maiúsculas diferentes, e na mesma coluna, médias seguidas por letras minúsculas diferentes, indicam diferenças estatísticas pelo teste de Tukey $(\mathrm{P}<0,05=*$ e $\mathrm{P}<0,01=* *)$; ${ }^{\mathrm{NS}}=$ Não significativo.

Fonte: Elaboração dos autores.

Tabela 7. Luminosidade e intensidade de amarelo da casca de ovos submetidos a diferentes tipos de revestimento e armazenados por 35 dias a $25^{\circ} \mathrm{C}$.

\begin{tabular}{ccc}
\hline Tratamento & Luminosidade (L) & Intensidade de amarelo \\
\hline Tipos de Revestimento (R) & & \\
Controle & $93,74 \mathrm{ab}^{1}$ & $3,55 \mathrm{a}$ \\
Óleo Mineral & $93,64 \mathrm{~b}$ & $3,35 \mathrm{a}$ \\
Gelatina a 3\% & $94,04 \mathrm{a}$ & $2,72 \mathrm{~b}$ \\
\hline Teste F & $4,66^{*}$ & $8,79^{* *}$ \\
DMS & 0,33 & 0,49 \\
\hline Per. de Armazenamento (A) & & \\
7 dias & $93,77 \mathrm{ab}$ & $1,98 \mathrm{~b}$ \\
14 dias & $93,43 \mathrm{~b}$ & $3,28 \mathrm{a}$ \\
21 dias & $93,85 \mathrm{ab}$ & $3,69 \mathrm{a}$ \\
28 dias & $94,15 \mathrm{a}$ & $3,47 \mathrm{a}$ \\
35 dias & $93,84 \mathrm{ab}$ & $3,64 \mathrm{a}$ \\
\hline Teste F & $4,02^{* *}$ & $14,12^{* *}$ \\
DMS & 0,50 & 0,74 \\
\hline F de interação R X A & $1,19^{\mathrm{NS}}$ & $1,36^{\mathrm{NS}}$ \\
\hline Coef. Variação & 0,57 & 24,88 \\
\hline${ }^{1}$ Na mesma coluna, médias seguidas de letras diferentes, indicam diferenças estatísticas pelo teste de Tukey $(\mathrm{P}<0,01=* * \mathrm{e}$ \\
$\mathrm{P}<0,05=*) ;$ NS= Não significativo. & & \\
Fonte: Elaboração dos autores. & &
\end{tabular}

Estes resultados mostram que o albúmen é mais sensível as alterações bioquímicas que ocorrem ao longo do tempo. As mudanças no $\mathrm{pH}$ ocorreram em virtude da maior perda de $\mathrm{CO}_{2}$ através dos poros da casca dos ovos sem revestimento (LI-CHAN; POWRIE; NAKAI, 1995), em conseqüência houve uma maior alcalinização, o que levou a uma maior liquefação dos mesmos, prejudicando os valores de unidade Haugh, já que o $\mathrm{pH}$ alcalino afeta a membrana interna (SCOTT; SILVERSIDES, 2000).
Esta liquefação do albúmen fez com que houvesse migração de água para a gema, aumentando assim o diâmetro desta, com conseqüente redução na sua altura, reduzindo o índice gema. Segundo Moreng e Avens (1990), o ovo recém posto apresenta cerca de $0,5 \%$ de $\mathrm{CO}_{2}$. A perda dessa substância durante o armazenamento resulta em alteração no sabor do ovo, devido ao aumento da alcalinidade alterando o pH de 7,6 para 9,5. 
Quanto às características de coloração da casca, pode-se observar (Tabela 8) que os ovos revestidos com gelatina apresentaram uma maior luminosidade e menor intensidade de amarelo $(\mathrm{P}<0,05)$ em relação aos ovos revestidos com óleo mineral, sendo que para luminosidade os ovos sem revestimento não diferiram dos demais tratamentos. No entanto, para a intensidade de amarelo o tratamento sem revestimento não diferiu do tratamento com revestimento com óleo mineral. Aparentemente, o uso de gelatina como forma de revestimento proporcionou uma coloração interessante ao produto ovo, visto que este se apresenta mais branco e brilhante.

\section{Conclusões}

Os revestimentos mostraram ser eficientes na manutenção da qualidade dos ovos durante o período de armazenamento, sendo que o revestimento com óleo mineral mostrou ser mais eficiente do que o revestimento de gelatina.

\section{Referências}

BACURAU, L. G.; ZAPATA, J. F. F.; FUENTES, M. F. F.; BARROSO, M. A. T.; SALES, M. G. Preservação de ovos de galinha por tratamento superficial de casca. Pesquisa Agropecuária Brasileira, Brasília, v. 29, n. 4, p. 643-651, 1994.

BERARDINELLI, A.; DONATI, V.; GIUNCHI, A.; GUARNIERI, A.; RAGNI, L. Effects of transport vibrations on quality indices of shell eggs. Biosystems Engineering, Harpenden, v. 86, n. 4, p. 495-502, dez. 2003.

CHERIAN, G.; LANGEVIN, C.; AJUYAL, A.; LIEN, K.; SIM, J. S. Research note: effect of storage conditions and hard cooking on peelability and nutrient density of white and brown shelled eggs. Poultry Science, Champaign, v. 69, n. 9, p. 1614-1616, set. 1990.

CRUZ, F. G. G.; MOTA, M. O. S. Efeito da temperatura e do período de armazenamento sobre a qualidade interna dos ovos comerciais em clima tropical úmido. In: CONFERÊNCIA APINCO DE CIÊNCIA E TECNOLOGIA AVÍCOLAS, 1996, Campinas. Anais... Campinas: FACTA, 1996. p. 96.
FAKHOURI, F. M.; FONTES, L. C. B.; GONÇALVES, P. V. M.; MILANEZ, C. R.; STEEL, C. J.; COLLARESQUEIROZ, F. P. C. Filmes e coberturas comestíveis compostas à base de amidos nativos e gelatina na conservação e aceitação sensorial de uvas Crimson. Revista Ciência e Tecnologia de Alimentos, Campinas, v. 27, n. 2, p. 369-375, abr.jun 2007.

KELL, G. S. Density, thermal expansivity, and compressibility of liquid water from $0^{\circ}$ to $150^{\circ} \mathrm{C}$ : correlations and tables for atmospheric pressure and saturation reviewed and expressed on 1968 temperature scale. Journal of Chemical and Engineeiring Data, Indiana, v. 20, n. 1, p. 97-105, 1975.

LANA, G. R. Q. Avicultura. Campinas. Livraria e Editora Rural, 2000. 268 p.

LI-CHAN, E. C. Y.; POWRIE, W. D.; NAKAI, S. The chemistry of eggs and egg products. In: STADELMAN, W. J.; COTTERILL, O. J. Egg science and technology. 4. ed. New York: Food Products Press, 1995. p. 105-175.

MENDONÇA, M. O.; REIS, R. S.; BARRETO, S. L. T.; MUNIZ, J. C. L.; VIANA, G. S.; MENCALHA, R.; FERREIRA, R. C.; RIBEIRO, C. L. N. Qualidade de ovos de codorna submetidos ou não a tratamento superficial da casca armazenados em diferentes ambientes. Revista Brasileira de Saúde e Produção Animal, Salvador, v. 14, n. 1, p. 195-208, 2013.

MORENG, R. E.; AVENS, J. S. Ciência e produção de aves. São Paulo: Rocca, 1990. 380 p.

MURAKAMI, A . E.; BARRIVIERA, V. A.; SCAPINELLO, C.; BARBOSA, M. J.; VALÉRIO, S. R. Efeito da temperatura e do período de armazenamento sobre a qualidade interna do ovo de codorna japonesa (Coturnix coturnix japonica) para consumo humano. Revista Unimar, Maringá, v. 16, p. 13-25, 1994. Suplemento 1.

NARUSHIN, V. G. Non-destructive measurements of egg parameters and quality characteristics. Poultry Science, Champaign, v. 53, n. 2, p. 141-153, 1997.

NONGTAODUM, S.; JANGCHUD,A.;JANGCHUD, K.; DHAMVITHEE, P.; NO, H. K.; PRINYAWIWATKUL, W. Oil coating affects internal quality and sensory acceptance of selected attributes of raw eggs during storage. Journal of Food Science, Chicago, v. 78, n. 2, p. S329-S335, 2013.

PLETI, A. K.; LIMA, J. J.; CANDIDO, L. M. B. Qualidade interna do ovo de avestruz após estocagem em temperatura ambiente e refrigerada. Ciência Rural, Santa Maria, v. 39, n. 6, p. 1864-1868, set. 2009. 
SCOTT, T. A.; SILVERSIDES, F. G. The effect of storage and strain of hen on egg quality. Poultry Science, Champaign, v. 79, n. 12, p. 1725-1729, dez. 2000.

SEIBEL, N. F.; BARBOSA, L. N.; GONÇALVES, P. M.; SOUZA-SOARES, L. A. Qualidade física e química de ovos de codornas alimentadas com dietas modificadas. Revista Instituto Adolfo Lutz, São Paulo, v. 64, n. 1, p. 58-64, 2005.

SOUZA, H. B. A.; SOUZA, P. A.; LIMA, T. M. A. Efeito da qualidade da casca e higienização com diferentes concentrações de hipoclorito de sódio na manutenção da qualidade interna de ovos de consumo. Alimentos $e$ Nutrição, Araraquara, v. 5, n. 1, p. 27-36. 1993.

SOUZA, H. B. A.; SOUZA, P. A.; BROGNONI, E.; ROCHA, O. E. Influência da idade sobre a qualidade dos ovos. Cientifica, São Paulo, v. 22, n. 2, p. 217-226, 1994.
STADELMAN, W. J. The preservation of quality in shell eggs. In: STADELMAN, W. J.; COTTERILL, O. J. (Ed.). Egg science and technology. $4^{\text {th }}$ ed. Westport, Conn.: AVI Publishing. 1995. p. 67-79.

UNIVERSIDADE FEDERAL DE VIÇOSA - UFV. Sistema de análises estatísticas e genéticas - SAEG. Versão 9.1. Viçosa, MG Imprensa Universitária, 2007.

WAIMALEONGORA-EK, P.; GARCIA, K.; NO, H. K.; PRINYAWIWATKUL, W.; INGRAM, D. Selected quality and shelf-life of eggs coated with mineral oil with different viscosities. Journal of Food Science, Chicago, v. 74, n. 9, p. 423-429, 2009. 